\title{
Tradisi Hermeneutika dan Penerapannya dalam Studi Komunikasi
}

\author{
R. Masri Sareb Putra \\ Universitas Multimedia Nusantara \\ J1. Boulevard, Gading Serpong \\ Telp.021-54220808,37039777, e-mail: masrisareb@yahoo.com
}

\begin{abstract}
ABSTRAK
Tradisi "hermeneutika" sudah dikenal dalam mitologi Yunani lewat figur Hermes yang dikenal piawai menafsirkan pesan "dunia atas" atau realitas ontologis untuk disampaikan kepada manusia. Kemudian, hermeneutika dipraktikkan para pakar untuk menemukan makna hakiki sebuah teks Akitab.

Sekolah Frankfurt kemudian mengembangkan metode hermeneutika sebagai cabang filsafat yang mencapai puncaknya pada Gadamer. Akan tetapi, hermeneutika baru menarik perhatian para pakar komunikasi Amerika pada 1976.

Di Indonesia, hermeneutika belum banyak digunakan untuk studi komunikasi, padahal hermeneutika dapat membongkar makna yang terselubung di balik realitas yang ada di balik teks dan wacana secara radikal.
\end{abstract}

Kata kunci: Hermeneutika, eksegese, makna, filsafat, komunikasi, wacana, teks.

\section{PENDAHULUAN}

Filsafat adalah induk dan cikal bakal dari semua ilmu (Grant, 1996; Barrett dan Aiken; 1962; Agushevits, 2008). Jika demikian, maka ilmu komunikasi yang kita kenal saat ini juga asal mulanya dari filsafat.

Sebagaimana diketahui bahwa makna atau true conditions adalah inti dari penelitian kualitatif. Hermeneutika ialah usaha rasional mencari makna suatu teks atau realitas dengan jalan menafsirkannya. Di dalam proses penafsiran tersebut, si penafsir dituntun oleh vorurteil (prejudice), yakni sejumlah pengalaman dan seperangkat pengetahuannya. Berdasarkan vorurteil tersebut, si penafsir coba mencari hakikat sebuah teks atau realitas dalam konteks sejarah dan tradisi pada saat teks atau realitas lahir. Inilah yang disebut "lingkaran hermeneutika", sebuah horizon yang terus berposes dan berkembang dalam usaha rasional menemukan hakikat.

Terkait dengan topik pembahasan, struktur paper ini mula-mula menggali lebih dahulu etimologi dan sejarah hermeneutika, praktik hermeneutika pada studi dan penafsiran Alkitab, hermeneutika sebagai cabang filsafat, dan pada bagian akhir bagaimana filsafat hermeneutika berproses dan berdialek- 
Tradisi Hermeneutika dan Penerapannya

dalam Studi Komunikasi
- R. Masri Sareb Putra tika sehingga diadopsi menjadi salah satu metode penelitian komunikasi untuk mencari makna (sensus plenior/true conditions) atau hakikat sesuatu lewat usaha rasional berupa penafsiran.

\section{PEMBAHASAN}

Menelisik kembali asal usul kata, kerap sangat membantu upaya kita memahami sesuatu. Dalam konteks ini, untuk memahami "hermeneutika", kita perlu terlebih dahulu menggali etimologinya.

Hermeneutika berasal dari kata Yunani hermeneūo yang berarti: saya menasfirkan. Terminologi ini dipetik dari nama Hermes dalam epik karya Homeros[1] yaitu Ililiad dan Odyssey. Dikisahkan bahwa Hermes adalah utusan dewa, ia mengemban tugas membawa pesan Zeus dari dunia dewa kepada alam manusia, terutama agar "bahasa dewa" dapat dimengerti dan diterjemahkan ke dalam "bahasa manusia" (Palmer, 1999). Hermes dikisahkan sangat piawai menasfirkan tanda yang diberikan dewa-dewa dan memiliki kemampuan menerjemahkan pesan-pesan tersebut dalam bahasa yang dapat dimengerti oleh manusia.

\section{SEJARAH HERMENEUTIKA}

Di dalam mengemban tugas tersebut, Hermes menjembatani apa yang disebut "gap ontologis" (ontological gap) yakni gap antara pemikiran atau alam dewa dan pemikiran atau alam manusia. Dalam mitos, dikisahkan bahwa Hermes memiliki kemampuan muncul dan menghilang kapan saja, punya kemampuan lari secepat kilat, dan punya daya magis untuk membuat orang tertidur atau bangun. Dikisahkan pula bahwa Hemes bukan hanya sanggup menjembatani antara jarak fisik (physical distance) dan jarak ontologis (ontological gap) antara dunia dewa (illahi) dan dunia manusiawi (Palmer, hlm. 2).

Tugas hemeneutika, seperti halnya tugas dewa, ialah: menjembatani gap antara ontologi (realitas) dan apa yang tampak di permukaan (fenomena). Dengan demikian, terjadi verifikasi sesuatu yang tampak di permukaan dengan substansi atau realitas yang merupakan "ada" atau being yang sesungguhnya. Inilah inti hermeneutika, sebagaimana namanya (dari nama dewa Hermes) yang piawai menafsirkan dan menjembatani jarak ontologis dunia dewa dan jarak fisik dunia manusia.

Dalam salah satu karya Aristoteles "De Interpretatione"[2] (tentang Interpretasi) kembali muncul istilah yang kurang lebih sama dengan Hermes, yakni "Peri Hermenias" yang mengacu kepada penafsiran dalam arti sempit, yakni penafasiran yang mengandung benar/salah. Dalam tradisi pemikiran Yunani, penafsiran seperti ini diarahkan pada teks pidato (retorika) seperti pidato Homeros dan syair-syairnya.

Pada abad pertengahan, para Bapa Gereja menafsirkan Alkitab secara lebih sistematis dan metodis dengan mencari makna alegorinya (sensus allegoricus) yang coba memahami teks berkenaan dengan isi doktrinal dari dogma Gereja, sehingga yang menjelaskan setiap elemen literal yang memiliki makna simbolis.

Hermenutika kemudian berkembang dan diadopsi para pakar Akitab (Kristen) yang mengembangkan studi penasfiran kitab suci secara ilmiah, dengan melihat konteks (kapan, di mana, lingkungan sosial budaya, serta ciri tekstual/struktur sastra) Alkitab tersebut untuk coba menangkap pesan (makna) yang dimaksudkan si penulis teks tersebut agar tidak bias dan maknanya tidak lari dari maksud si penulis.

Dalam metode penasfiran Alkitab[3] tersebut, sejarah dan tradisi tidak boleh lepas dari konteks. Oleh karena itu, metodologinya disebut "eksegese" (penafsiran), yakni sebuah usaha rasional melakukan interpretasi secara sistematis. Cara kerja seperti ini hanya dapat ditemukan pada Philo dari Aleksandria, yang melakukan refleksi tentang makna alegoris dari Perjanjian Lama yang berasumsi bahwa makna literer dari sebuah teks dapat menyembunyikan arti non-literer (true conditions) yang hanya dapat ditelusuri melalui kerja interpretasi yang sistematis. 
St. Origenes (185-254) dari Alexandria selanjutnya mengembangkan studi interpretasi Kitab Suci secara sistematis dan dengan berani menyatakan bahwa Alkitab memiliki tiga tingkatan makna, seperti bangun segitiga yakni: tubuh, jiwa, dan semangat yang masingmasing mencerminkan tahap yang semakin lebih maju kepada pemahaman Kitab Suci secara lebih menyeluruh dan mendekati kepenuhan atau plenior (Seiler, 1835: 4). Dengan kata lain, Alkitab dilihat bukan semata-mata sebuah teks-tertulis per se (tubuh), akan tetapi Alkitab juga memiliki dimensi makna (jiwa), dan dimensi power atau semangat yang dapat menggerakkan orang (afeksi, kognisi, dan behavioral). Konsep segitiga "temuan" Origenes ini nantinya memengaruhi teori-teori psikologi, yang selanjutnya mempengaruhi teori komunikasi, terutama mengenai dampak dari isi atau pesan komunikasi.[4]

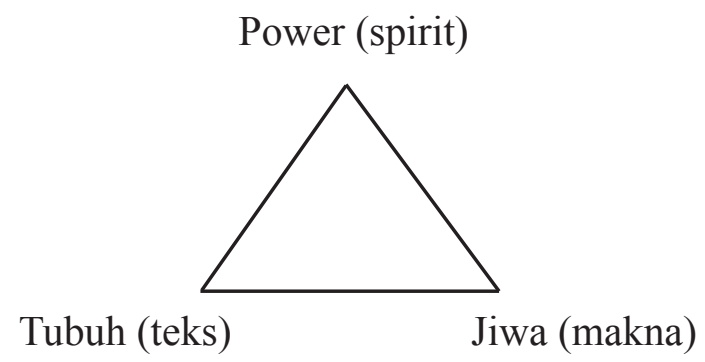

Gambar 1: Segitiga tingkatan makna Alkitab menurut St. Origenes

Selanjutnya, St. Agustinus dari Hippo (354-430) adalah salah seorang pemikir yang berpengaruh terhadap hermeneutika modern seperti diakui oleh Dilthey, Heidegger, dan Gadamer. Menurut Gadamer, justru Augustinuslah yang pertama kali memperkenalkan universalitas hermeneutika. Pernyataan ini didasarkan pada bagaimana Agustinus memandang hubungan antara bahasa dan interpretasi, juga bagaimana penafsiran Kitab Suci melibatkan tingkatan yang lebih eksistensial dari sekadar pemahaman atas teks itu sendiri. Karya Thomas Aquinas (Summa Theologia), di mana Heidegger banyak men- curahkan perhatian dan mendapatkan inspirasi, juga berpengaruh pada perkembangan hermeneutika modern. Sebagaimana diketahui bahwa Thomas Aquinas membagi empat lapis makna Alkitab, yakni

1) the literal or historical level (Alkitab sebagai teks itu sendiri),

2) the allegorical[5] level (peristiwa literal berkaitan dengan pristiwa Perjanjian Baru),

3) the moral level (menjelaskan pelajaran abstrak moral yang bisa ditarik dari peristiwa literal), dan

4) the anagogical level (yang berkaitan dengan makna) yang juga kerap disebut sebagai "heavenly things".

Layer yang keempat ini oleh Brown disebut sebagai "sensus plenior" yakni fuller sense atau cita rasa yang purna dari Alkitab. Inilah makna yang sesungguhnya dari seluruh kegiatan penafsiran, yakni upaya menemukan true conditions, sesuai dengan arti anagoge: tingkatan tertinggi yang melampaui apa yang kelihatan.

Filsuf lain yang turut mempengaruhi tahap awal hermeneutika modern adalah Spinoza. Dalam bab ketujuh dari Tractatus theologicopoliticus (1670), Spinoza mengusulkan bahwa untuk memahami bagian paling esensial dan paling sulit dari Kitab Suci, si penafsir haruslah berangkat dari cakrawala historis di mana teks-teks tersebut ditulis dan merekonstruksi bagaimana Alkitab tersebut diproduksi. Dengan demikian, Alkitab bukanlah pertama-tama sebuah teks-mati, melainkan mengandung makna terdalam seperti dicatat Caroll (2002:6) bahwa

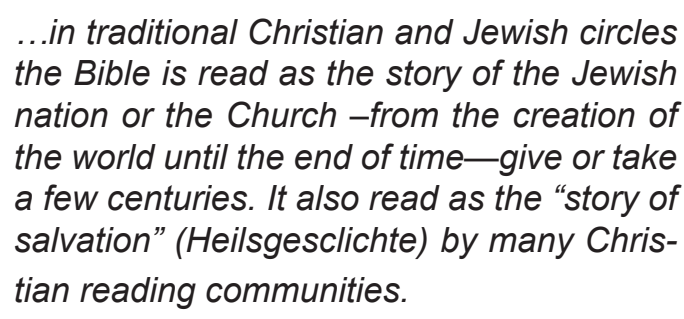

Selanjutnya, Caroll (hlm. 7) menekankan bahwa tradisi hermeneutik Kristen di dalam 
menafsirkan Alkitab tidak pernah lepas-lepas, melainkan selalu dilihat secara "intertextual".

Jalan dialektika bagaimana para pakar dalam tradisi Kristen menafsirkan Alkitab secara hermeneutik seperti dilukiskan di atas panjang sekali. Sejarah dan tradisi menafsirkan itu sendiri adalah kegiatan hermeneutik di mana konteks tradisi dan sejarah tidak dapat dilepaskan dari sang penasfir, sehingga mereka bersepakat memandang bahwa Alkitab pertama-tama bukanlah sebuah teks-mati; namun harus dapat menangkap maknanya yang terdalam pada tataran anagogical atau sensus plenior. Dalam perkembangan selanjutnya, metode eksegese ini juga dipakai ilmu sastra (menasfirkan teks/terjemahan) dan psikologi (menafsirkan mimpi).

\section{TIPE-TIPE HERMENEUTIKA}

Menurut Palmer (1999), selain Gadamer, terdapat dua belas filsuf yang pemikiran dan karyanya berkorelasi dengan hermeneutika yakni:

1) Plato (metode dialogis yang dikembangkannya dari Sokrates, mitos tidak bertentangan dengan rasio/logos)

2) Aristoteles (Organon, terutama de Interpretatione)

3) Hegel (dialektika: tesis, antitesis, sintesis)

4) Husserl (fenomenologi)

5) Heidegger (fenomenologi, terutama Being and Time)

6) Wittgenstein (filsafat bahasa)

7) Adorno (teori kritis Frankfurt School)

8) Habermas (hermeneutika salah satu dimensi teori kritik sosial).

9) Derrida (mendekati hermeneutika dari latar post-structuralist theory)

10)Foucault (strukturalis/ "interpretative analytics").

11) Rorty (menggunakan hermeneutika untuk membangun posisi menentang epistemologi yang berbasis-filsafat, masa lampau, dan masa kini)

12)Davidson (menafsirkan Alkitab sebagai dialog hermeneutikal)

\section{TUJUAN YANG INGIN DICAPAI DARI HERMENEUTIKA}

Tentu saja, dalam kertas kerja ini tidak mungkin membahas secara mendetail semua pemikiran para filsuf tersebut terkait dengan hermeneutika. Untuk itu, akan dipilihkan beberapa saja yang dianggap mewakili atau dianggap cukup fenomenal baik karena pemikirannya yang luar biasa maupun karena diakui berjasa meletakkan fondasi bagi pemikiran dan metode hermenutika.

Oleh karena Gadamer dianggap sebagai "bapak hermeneutika modern" maka porsi pembahasannya cukup panjang lebar, terlebih lagi mengingat bahwa hermeneutika Gadamer diadopsi para pakar untuk membangun teori komunikasi (Deetz, 1976; Palmer, 1999). Dengan demikian, mengelaborasi bagaimana filsafat hermeneutika berproses dan berdialektika menjadi teori komunikasi sangatlah menarik dan sangat relevan dengan perkuliahan "Metodologi Penelitian Kualitatif". Sekaligus melalui usaha elaborasi ini dipaparkan bagaimana proses terjadinya konsep dan teori baru dalam ilmu komunikasi-dalam hal ini hermeneutika-- dan bagaimana para tokoh membangun teori ini secara induktif-logis. Pada akhirnya, hermeneutika adalah upaya rasional menafsirkan realitas (ontologis) untuk mengungkapkan hakikat atau substansi yang sesungguhnya dari segala sesuatu yang ada (being) yang dalam bahasa teknis-ilmiah disebut sebagai "true conditions".

Menurut Ricour (1991), hermeneutika ialah "the theory of operations of understanding in their relation to the interpretation of text (1991: 53).

Dengan kata yang sederhana dapat disebutkan bahwa metode filsafat hermenutika ialah: kegiatan olah pikir yang menafsirkan dan memahami makna suatu teks (realitas) secara rasional untuk mencari/menemukan hakikatnya.

Filsafat hermenutika dibangun dan dipengaruhi oleh filsafat fenomenologi. Tokohnya adalah Schleiermacher, Dilthey, Hegel, dan Heidegger[6]. Gadamer yang dianggap 
sebagai filsuf hermeneutika modern dipengaruhi oleh fenomenologi Heidegger (terutama melalui Being and Time) karena Gadamer adalah murid Heidegger. Pengaruh pemikiran fenomenologi[7] ini nantinya cukup kental dalam karya Gadamer yakni Wahrheit un Methode (1960) atau Truth and Method dan atas "temuan"-nya ini Gadamer dipandang sebagai tokoh filsafat hermenutika modern yang mengelaborasi penafsiran sebagai usaha memahami realitas yang hakiki dalam konteks sejarah dan tradisi.

Gadamer menegaskan bahwa kontemplasi metodikal berlawanan dengan pengalaman dan refleksi. Menurut Gadamer, manusia dapat meraih kebenaran hanya dengan mengerti atau bahkan menguasai pengalamannya. Oleh karena metode hermeneutika mengandalkan olah akal budi rasional dalam upaya memahami realitas/ontologi (menafsirkan teks) dan kontemplasi ini maka hermeneutika oleh Habermas disebut sebagai metode kritis (Wachterhauser, 1986: 243-276) dan oleh Ricoeur disebut sebagai "kritik atas ideologi" (Wachterhauser, hlm. 400).

Pengalaman, menurut Gadamer, tidaklah tetap, melainkan berubah-ubah; dan pengalaman tersebut selalu menunjukkan perspektif waktu. Gadamer menunjukkan pada kita bahwa kita tidak pernah dapat melangkah keluar dari tradisi. Oleh karena itu, yang dapat kita lakukan adalah: berusaha atau mencoba untuk memahami tradisi tadi. Konsep atau proposisi ini kemudian mengelaborasi atau menguraikan gagasan tentang lingkaran hermeneutika.

Bagi Gadamer, sejarah bukanlah milik kita, tetapi kita adalah milik sejarah. Lama sebelum kita bisa memahami diri kita (autos hepa), kita memahami siapa diri kita dalam cara yang terbukti dengan sendirinya, yakni kita ada dalam keluarga, masyarakat, negara, dan tempat tinggal kita (tradisi). Inilah yang disebut dengan "realitas historis". Konsep yang penting dalam pandangan Gadamer ialah bahwa Gadamer melihat realitas sebagai sebuah teks. Gadamer juga meyakini bahwa jika kita mengerti teks maka penasfiran adalah metode [8] atau jalan untuk mencapai pengertian yang ada di balik teks tersebut. Dengan demikian, Filsafat Hermeneutik adalah kritis, bahkan cenderung skeptis (salah satu sikap ilmuwan untuk tidak mudah percaya begitu saja).

Ketika kita menafsirkan teks, maka ada jarak waktu (dialektis). Teks mempengaruhi saya. Terjadi proses dialektis antara teks dan saya, oleh karena itu, ada horizon.

Teks juga dimengerti dalam dialektis perpaduan horizon. Jadi, tahap ini aktual tidak hanya pada zaman dulu. Di dalam upaya memahami realitas sebagai teks: ada vorurteil (prejudice), praduga. Vorurteil ini dipakai untuk membaca teks. Inilah syarat supaya pemahaman akan sebuah teks terjadi.

Dengan demikian, menurut Gadamer, pengalaman individu selalu hermeneutik, selalu berkembang dalam proses penafsiran. Karena itu, pengalaman negatif dalam teks harus dipelajari dengan baik. Sejarah yang negatif, misalnya Gerakan 30-S/PKI dan Tragedi Mei 1998, karena itu, menjadi penting. Mengapa? Karena peristiwa tersebut merupakan "peristiwa sosial" yang dalam bahsa Ricoeur disebut sebagai "symbol of evil" [9] dan hanya dapat dipahami secara utuh-menyeluruh dalam konteks sejarah. Sebagai contoh, (teks) lagu "Genjer-Genjer", hanya dapat dimengerti secara purna apabila dikaitkan dengan peristiwa sosial jelang G30S/PKI tahun 1965. Bagi para saksi sejarah yang hari ini masih hidup lagu tersebut adalah sebuah "teks" yang mengandung realitas ontologis yang, apabila ditafsirkan dalam konteks sejarah pada waktu itu, dapat menyingkap banyak hal. Sebaliknya, bagi generasi sekarang, lagu yang sama hanyalah sebatas teks (tubuh) saja.

Demikian halnya dengan teks atau tulisan "Milik Pribumi" yang ditulis di tembok, depan toko, ruko, atau barang-barang tertentu pada Kerusuhan Mei 1998. Teks tersebut untuk saat ini "tidak berbunyi" apabila tidak dikaitkan dengan sejarah atau peristiwa sosial pada saat itu. Amuk massa sebagai pelampiasan 
Tradisi Hermeneutika dan Penerapannya

dalam Studi Komunikasi kekecewaan dan dendam yang terpendam pada Pemerintahan Orde Baru dilampiaskan pada kalangan nonpri, sehingga apa pun yang menyimbolkan nonpri halal untuk dirusak dan dijarah; namun "milik pribumi" haram hukumnya untuk diganggu, apalagi dirusak. Makna terdalam atau sensus plenior dari teks "Milik Pribumi" hanya dapat dimengerti dalam konteks sejarah dan pengalaman kolektif pada saat itu dan pendekatan hermeneutika dapat menjelaskan makna di balik sebuah teks.

Dalam konteks itulah Gadamer berpandangan bahwa hermeneutika adalah metode yang terus berproses dalam lingkaran historis sebagai usaha rasional untuk memahami ontologis. Teks adalah realitas yang tampak, teks yang tampak tersebut haruslah ditafsirkan dalam tiga dimensi: 1) psikologis, 2) struktur, dan 3) historis untuk menemukan kebenaran (realitas) yang sejati -yang dalam bahasa Thomas Aquinas disebut sebagai "anagogical level", upaya menemukan sensus plenior dari sesuatu.

Jadi, what is truth? Teks adalah petunjuk (clue) to something. Aletheia (kebenaran) menampakkan diri dalam seluruh dialektis (interaksi antara aku-teks: aku sebagai si penafsir dan teks sebagai objek yang ditafsir) dan agar sampai pada pemahaman yang purna (sensus plenior) mengenai hakikat segala sesuatu yang ada (being) maka interaksi aku-teks ini berlangsung dalam lingkaran hermeneutika.

\section{HERMENEUTIKA SEBAGAI METODE PENELITIAN KOMUNIKASI}

Menurut Gadamer, manusia adalah makhluk yang tidak dapat lepas dari bahasa. Melalui bahasa, dunia ini terbuka bagi kita. Kita belajar untuk mengetahui dunia dengan belajar menguasai bahasa. Oleh karena itu, kita tidak dapat benar-benar memahami diri kita kecuali kita memahami diri sebagai bagian dari budaya dan bahasa dalam dimensi ruang dan waktu yang menyejarah. Hal ini membawa konsekuensi dalam pemahaman kita tentang seni, budaya, dan sejarah teks. Sejarah (teks) merupakan bagian dari tradisi kita sendiri, karya-karya sejarah tidak terutama menampilkan diri kepada kita sebagai objek netral dan bebas-nilai dari penyelidikan ilmiah. Sejarah (teks) adalah bagian dari cakrawala di mana kita hidup dan melalui cakrawala tersebut pandangan kita terhadap dunia akan dibentuk. Dengan kata lain, kita dibentuk oleh karyakarya besar (tradisi dan histori) sebelum kita mendapatkan kesempatan untuk mendekatinya dengan tatapan yang objektif.

Melalui usahaa interpretatif untuk memahami realitas yang sejati, kita mendapatkan pemahaman yang lebih baik dan lebih mendalam tidak hanya sebatas apa yang disajikan oleh teks yang menurut istilah Origenes "tubuh", akan tetapi juga memahami diri kita sendiri (autos hepa). Hal inilah yang diangkat Deetz (1976) dalam Kolokuium Komunikasi Verbal di Florida, Juli 1976. Deetz antara lain menekankan hal yang berikut ini.

However, when these concepts are taught and make their way into everyday language, they are often understood as representing things rather than experiences and process. "self," "attitudes," norms," "culture," and so forth are example of concepts suffering from this reification. Explanation using these concepts in understood as one thing causing another rather than chosen way of structuring the experience on continuity. The experience is thus explained away in abstraction rather than brought to clearer understanding. For example, what does it mean to say that a communication problem is a result of cultural differences? And how does that move us towards solving the problem? Concepts do not need to be seen as tools of classification (in a categorical sense) but can be seen as opening experience in interpretative sensee." (Deetz, hlm. 23-24).

Pemahaman akan realitas sejati dan pemahaman akan diri ini terus-menerus berproses dalam apa yang dinamakan "lingkaran hermeneutik" seperti gambar berikut ini di mana teks (realitas) terus berputar dan tidak pernah selesai. 

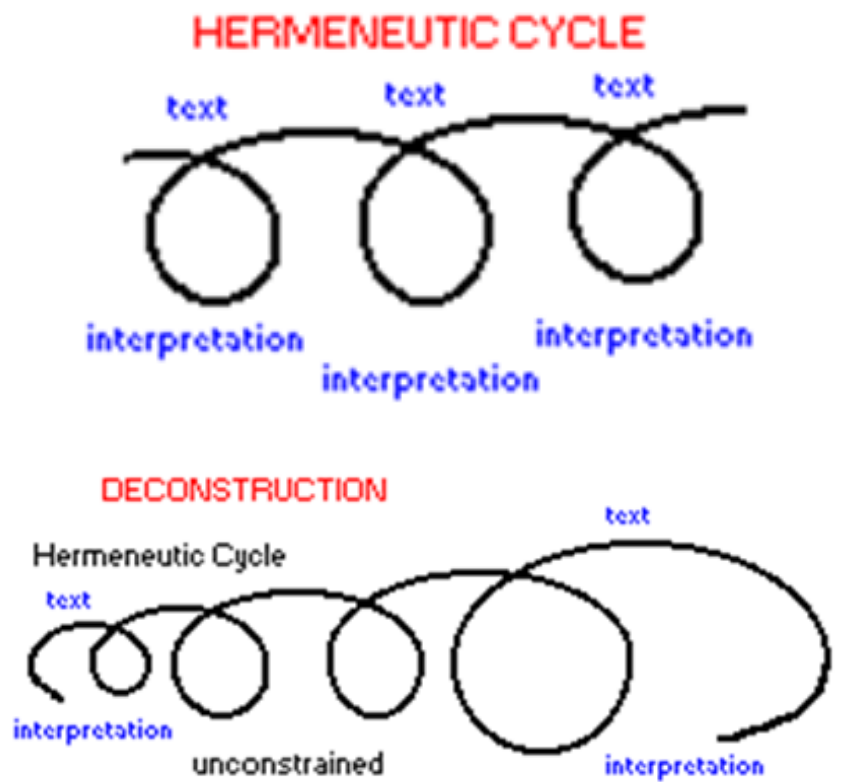

Gambar 2: Lingkaran hermeneutika Sumber: http://www.friesian.com/hermenut.htm

Dalam upaya memahami sebuah teks secara utuh-menyeluruh maka interpretasi harus terus-menerus mengikutinya. Dalam konteks inilah penafsiran harus diletakkan dalam dimensi waktu (sejarah) dan tradisi -sesuatu yang mengingatkan kita akan Berger dan Luckmann[1] (1966) mengenai kesadaran kolektif yang membentuk konsepsi mengenai realitas sosial.

Relasi antarmanusia dan kesadaransejarah ini kembali ditekankan Deetz (hlm. 24) bahwa hermeneutika, terutama Gadamer, memberikan kontribusi penting bagi studi komunikasi yang intinya ialah bahwa: makna (true conditions) dari segala sesuatu yang ada baru dapat dipahami seutuhnya jika dikaitkan dengan kesadaran-sejarah (historical consciousness).

Apa relevansi filsafat hermenutika dengan studi-studi ilmu komunikasi? Deetz menyebutkan bahwa hermeneutika sangat menarik bagi para pakar ilmu komunikasi Amerika. Alasannya: metode filsafat hermeneutika sangat cocok dan relevan untuk studi komunikasi, terutama karena hemerneutika membantu studi komunikasi di dalam "understanding the message becomes primarily an instrumental act towards this end" (Deetz, hlm. 10).
Di tempat lain, Palmer dalam "The Relevance of Gadamer's Philosopical Hermeneutics to Thirty-Six Topics or Fields of Human Activity" menyebutkan terdapat 36 topik yang relevan dengan filsafat hermeneutika Gadamer, salah satu di antaranya untuk studi komunikasi, yakni topik ke-35 "Communication Theory", terutama menyangkut bahasa sebagai alat komunikasi (verbal), bagaimana bahasa bekerja, serta bagaimana metode penasfiran hermeneutika Gadamer dipakai untuk menafsirkan metabahasa atau realitas di balik bahasa verbal.

Sebagai metode dalam penelitian/studi komunikasi, hermeneutika mengikuti langkah yang berikut ini:

1) Menetapkan being atau objek material (teks, objek, fenomena) yang hendak diselidiki atau diamati.

2) Berusaha menafsirkan being tersebut dengan mengikuti "segitiga" tingkatan makna Origenes.

3) Lalu berupaya mencari sensus plenior (hakikat terdalam/true conditions) dari being tersebut.

4) Jika si penafsir yang sudah sampai pada sensus plenior di mana ia sudah berhasil menjadi jembatan (mediator/messenger) dan berhasil menunaikan tugas seperti yang dilakukan Hermes yaitu berhasil menjembatani gap ontologis realitas yang sesungguhnya dengan apa yang tampak, maka hermeneutika sudah sampai pada metode penelitian kualitatif: menemukan makna terdalam dari segala sesuatu yang ada (being).

\section{PROSES KESAHIHAN DAN KEABSAH- AN DATA}

Terdapat beberapa faktor yang memengaruhi kesahihan data (validitas) dan keandalan (realibilitas) data dalam penelitian kualitatif, yakni nilai subjektivitas, metode pengumpulan data, dan sumber data dalam penelitian. Dalam hermeneutik, si penafsir adalah subjek yang tidak dapat dihindarkan karena di dalam upaya memahami makna sebuah realitas (teks) ia berada pada posisi menafsirkan dan dalam 
Tradisi Hermeneutika dan Penerapannya

dalam Studi Komunikasi
- R. Masri Sareb Putra penafsiran tersebut di balik kepala si subjek diandaikan adanya vorurteil, prejudice[11] (Gadamer,273 ) “Actually 'prejudice' means a judgement that is rendered before all the elements that determine a situation have been $f$ nally examined. In German legal terminology a 'prejudice' is a provisial legal verdict before the final verdict is reached."

Cita rasa prejudice dalam bahasa Inggris tidak sepenuhnya dapat menjelaskan apa yang Gadamer maksudkan sebagai vorurteil yang dalam bahasa Latin, praejudicium yang berarti: adverse effect, disadvantage, harm. Cita rasa negatif kata tersebut hanyalah derivatif, konsekuensi negatifnya sangat bergantung pada validitas positif, nilai dari "provisial decission" sebagai prejudgement, sebagaimana halnya setiap preseden. Dengan demikian, "prejudice" sebagaimana dimaksudkan Gadamer, ialah "certainly does not necessarily mean a false judgement, but part of the idea is that it can have either a positive or negative value." (Gadamer, hlm. 273).

Dengan demikian, "subjektif" dalam hermeneutika tidak identik maknanya dengan subjektif sebagaimana yang kita mengerti sehari-hari, yakni mengenai atau menurut pandangan (perasaan) sendiri, tidak langsung mengenai pokok atau halnya (Kamus Besar Bahasa Indonesia, 2007: 1095).

Metode pengumpulan data dalam studi hermeneutika ialah bahwa data terdapat dalam teks atau dalam wacana. Dapat tunggal ( $d a-$ tum) dapat juga jamak (data) bergantung pada sifat atau lingkup unit analisisnya.

Adapun sumber data dalam penelitian hermeneutika haruslah orisinal atau sumber primer.

\section{PENERAPAN METODE HERMENEUTI- KA DALAM STUDI KOMUNIKASI}

Oleh pakar komunikasi, hermeneutika dimasukkan ke dalam teori kritis (Littlejohn, 2009: xiv; 469-474). Diakui bahwa metode hermeneutika memberikan perspektif baru dalam studi komunikasi.

\begin{abstract}
"At the heart of hermeneutics is a novel view of the structure of discursive understanding, which it takes to be circular rather than linear. Analytic logic moves one step at a time toward a conclusion and attempts to exclude presuppositions or predeterminations. Hermeneutics not only affirms the impoverishment of this kind of thinking, but it makes predispositions and prederminations constitutive and central to the communication process itself.",
\end{abstract}

Hermeneutika ialah upaya rasional mencari dan menemukan makna atau sensus plenior dari sebuah teks (realitas); sementara hakikat dari penelitian kualitatif juga mencari makna hakiki dari being, segala sesuatu yang ada yang hendak diteliti.

Sebagai contoh, seseorang hendak meneliti teks/wacana Orde Baru yakni "amankan". Mendapatkan prefiks ke-an, kata dasar wacana ini adalah "aman" yang berarti: bebas dari gangguan, terlindung atau tersembunyi, tenteram[12]. Arti kamus ini menurut Origenes adalah "tubuh" atau teks per se. Untuk mengerti makna dan peristiwa (sosial) di balik teks "amankan" ini, kita (peneliti) harus dapat menangkap jiwa dari kata tersebut, yaitu bukan benar-benar terlindung atau tenteram sebagaimana tersurat dalam pengertian kamus; sebaliknya seseorang yang "diamankan" dalam konteks sejarah Orde Baru justru berarti hilang (diculik atau dibunuh) agar yang bersangkutan tidak mengganggu sepak terjang dan menghalang-halangi penyelenggaraan pemerintahan pada saat itu.

Makna terdalam dari wacana ini dapat dijelaskan dengan pendekatan hermeneutika, yakni dengan mencari sensus plenior-nya, tidak hanya sebatas teks saja. Jika hanya menelaah teks maka makna hakiki dari wacana tersebut tidak terungkap. Untuk mengungkap secara utuh-menyeluruh teks tersebut, pendekatan hermeneutika dapat membantu dengan menempatkan objek material (unit analisis) "amankan" ke semua aras dari bangun segitiga Origenes dan mengangkatnya ke aras anagogikal (anagogical level) sebagaimana yang disarankan oleh Thomas Aquinas. Kemu- 
Tradisi Hermeneutika dan Penerapannya dalam Studi Komunikasi

dian, menempatkannya dalam konteks sejarah (dan tradisi) sesuai dengan yang dianjurkan Gadamer di mana aku (penafsir) terus-menerus berdialog dengan teks, dan dalam dialektika tersebut, ada horizon yang memungkinkan sebuah teks atau realitas ditangkap secara utuhmenyeluruh. Penafsiran (hermeneutika) ini berlangsung dalam sebuah siklus yang disebut "lingkaran hermeneutika".

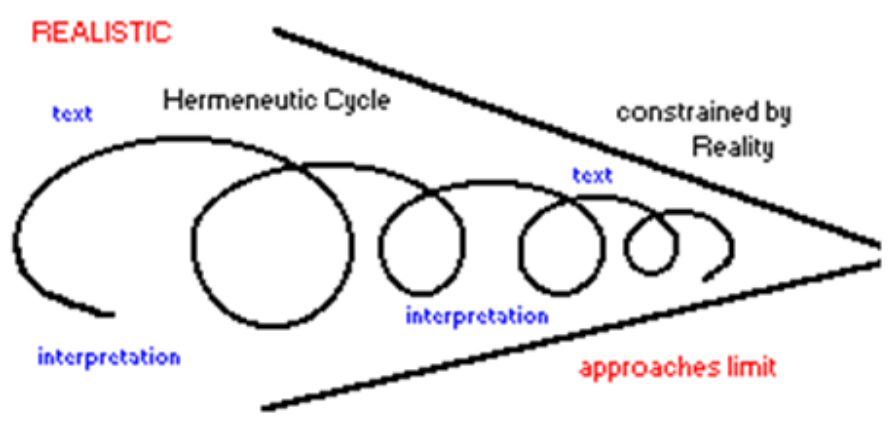

Gambar 3: Tampilan struktur spiral turun yang sama dengan tabel "siklus realistis hermeneutika" Sumber: http://www.friesian.com/hermenut.htm

Sebagaimana tampak dalam gambar di atas, penafsiran hermeneutik dibatasi oleh teks, atau oleh bukti empiris, atau oleh hal lain, sehingga ada kemungkinan bahwa siklus hermeneutik justru bukan mempersempit spiral di luar kendali. Limit dari spiral, apakah tercapai atau tidak, merupakan prinsip objektivitas dan realitas. Seperti dalam mekanika kuantum itu sendiri, akan ada kisaran yang lebih besar atau lebih kecil dari ketidakpastian, tetapi ini hanyalah kisaran, bukan sebuah kemungkinan tak terhingga atau tak terbatas.

Jika teks "amankan" dimasukkan ke dalam siklus hermeneutika dan coba dicari maknanya yang paling hakiki maka aku (penafsir) terus-menerus berdialog dengan teks (realitas), di dalam proses dialektis tersebut ada jarak waktu tersebut ada horizon yakni garis yang sejajar antara batas pendekatan atau usaha rasional untuk mengerti teks (approach limit) dan dan garis batas ontologis yang (masih) terkendala oleh realitas. Gap antarkedua garis ini yang coba dijembatani atau dihubungkan si penafsir dan dalam horizon yang bersifat dialektis inilah si penafsir menemukan kepurnaan makna sebuah teks.

Dengan demikian, teks "amankan" yang ontologis sebagai "bahasa dan jargon dewa" berusaha dijembatani oleh si penafsir dengan menemukan sensus plenior-nya pertama-tama memang melalui salah satu kaki segitiga Origenes yakni "tubuh/teks". Akan tetapi, hal yang jauh lebih penting setelah itu ialah melihat kaki-kaki yang lain, yakni jiwa dan spiritnya dalam peristiwa sejarah dan keadaan pada saat itu. Begitu dari dunia dewa datang titah untuk "mengamankan" seseorang maka itulah isi pesan yang langsung dapat dimengerti warga dunia atas, namun yang tidak sepenuhnya dimengerti orang kebanyakan. Si penafsir akan bertindak selaku Hermes dan ia akan menjadi mediator antara dunia dewa dan dunia manusia, sehingga manusia yang melaksanakan pesan itu di lapangan melakukan apa yang dikehendaki dewa.

Dalam upaya menemukan sensus plenior inilah agaknya kita memahami apa yang ditekankan Gadamer berikut ini.

All the beginning of all historical hermeneutics, then, the abstract thesis between tradition and historical research, between history and the knowlede of it, must be discarded. The effect (Wirkung) of a living tradition and effect of historical study must constitute a unity of effect, the analysis of which would reveal only a texture of reciprocal effects. Hence we would do well not regard historical consciousness as something radically new -as it seems at first-but as a new element in what has always constituted the human relation to the past. In other words, we have to recognize the element of tradition in historical research and inquire into its hermeneutic productivity.

That element of tradition affects the human sciences despite the methodical purity of their procedures, an element that constitutes their real nature and distinguishing 
Tradisi Hermeneutika dan Penerapannya dalam Studi Komunikasi

mark, is immediately clear if we examine the history of research and note the difference between the human and the natural sciences with regard to their history. Ofcourse none of man's finite historical endeavors can completely erase the trace of this finitude. (Gadamer, hlm. 283-284).

Dalam upaya mencari dan menemukan kepurnaan makna teks "amankan" maka pendekatan hermeneutika pertama-tama harus menempatkan teks tersebut dalam bingkai sejarah untuk menemukan sensus plenior-nya. Aspek kesadaran akan sejarah dan vorurteil inilah yang membedakan Gadamer dari Habermas seperti yang dicatat Palmer.

What separates Heidegger and Gadamer is Gadamer's concept of wirkungsgeschichtliches Bewußtsein, a consciousness in which history is always at work. For Gadamer there is no escape from history or from prejudices, although one must continually become aware of them. But they are the basis of our understanding at all, so "prejudgments" are always already there (Palmer).

Gadamer memandang teks (bahasa) sebagai "the house of Being". Untuk mengungkap sekaligus menemukan makna yang purna dari "Being" tersebut, pertama-tama si penafsir haruslah lebih dahulu masuk ke dalam rumah Being dimaksud sebagai upaya awal mengurai apa yang oleh Gadamer disebut sebagai "hermeneutic circle". Dari perspektif studi komunikasi, menurut Boldonova (2008: 504), konsep lingkaran hermeneutik ini penting untuk diurai karena

...hermeneutic circle provide the explanation of the circular movement of understanding, which runs from the part of the conversation to the whole conversation, and back. The interlocutor calls the expectation of meaning a force-conception of completeness: this solve the problem of contradiction between something unknown and the familiar.
Menurut Gadamer, hermeneutic circle adalah dialektika antara knowledge and fore-knowledge. Dialektika tersebut tidak lain tidak bukan adalah apa yang disebut sebagai "temporal distance" yakni jarak antara dua horizon: horizon masa lampau yang menyejarah (the horizon of the past) dan horizon masa kini (the horizon of present).

The horizon of the past (of an object itself) ialah bingkai tempat segala sesuatu terjadi atau tempat peristiwa historis berlangsung. Sementara the horizon of present (of an interpreter) ialah segala usaha yang coba memahami dan menginterpretasi suatu objek atau peristiwa.

Salah satu aspek penting dari hermeneutik kontemporer ialah sudut pandang bahwa setiap usaha yang dianggap berhasil dari pemahaman atau interpretasi suatu teks (realitas) ialah memahami hakikatnya. "... in order to understand Gadamer's contribution to the study of interpersonal understanding, one must realize that understanding is communicative." (Boldonova, hlm. 490).

Apabila sang interpreter atau penafsir berhasil memecahkaan persoalan antara something unknown and the familiar -- yang dalam istilah filsafat menjembatani antara jarak fisik (physical distance) dan jarak ontologis (ontological gap)-- maka ia sama melakukan tugas seperti dilakukan Hermes.

Komunikasi dan pemahaman tejadi ketika interlokutor mencapai kesepahaman (commonality). Gadamer menyebut ini sebagai fenomenon fusi dari horizon (fusion of horizon) dan menggambarkan tipe ini sebagai "konversasi hermeneutik" ketika makna yang sama sudah terbangun.

Menurut Boldonova (hlm. 496) konsep hermeneutik lain dari Gadamer dapat juga diterapkan pada komunikasi antarpribadi. " $A p$ plication is connected with feedback is the form of verbal expression or actions as a result of understanding. In interpersonal communication, interlocultors must have proper listening skills, interpretative competence, and the 
ability to give immediate feedback."

Sumbangan hermeneutika, terutama Gadamer, untuk studi komunikasi tidak diragukan lagi seperti dicatat Deetz berikut ini.

\begin{abstract}
Gadamer would have communication studies become aware of time not as a variable to be considered as "timing" not as something along side interaction (as interaction happens through time) but as an integral part of the structure of interaction itself.... Meaning is not extra wordly ut is subject to change in time and thus open to new significance. Meaningful everyday interaction like a great literary work is never closed in meaning but able to speak again in a different but significant way.... Communication directed toward increased understanding is opening of meaning to time and change and the interactants to new experience (Deetz, hlm. 18).
\end{abstract}

Deetz sesungguhnya menegaskan kembali makna sebuah teks sebagaimana dikatakan Gadamer, "... the task of understanding is concerned in the first place with the meaning of the text itself (Gadamer, hlm. 335). Adapun kriteria untuk memahami sebuah teks "The criteria for understanding must be the harmony of all the details itself (Gadamer, hlm. 259). Dengan kata lain, makna sebuah teks dipahami secara intertextual.

Akhirnya, Deetz menyimpulkan bahwa hermeneutika terutama memberikan sumbangsih bagi studi komunikasi untuk mengkonstruk body of knowledge. "It should clear that Gadamer's analysis of character of undertanding makes problematic the basic assumed goal of communication studies to construct a body of knowledge" (Deetz, hlm. 22).

\section{SIMPULAN}

Relevansi filsafat hermeneutika dalam studi komunikasi ialah: Filsafat hermeneutika memberikan kontribusi pada studi komunikasi untuk melihat realitas di balik data (meta data), menyingkap meta-teks dengan coba membongkar ada apa di balik teks tersebut, meny- ingkap realitas di balik data yang terselubung, dan bagaimana menangkap makna di balik halhal yang tampak di permukaan (ucapan, teks, gesture).

Hermeneutika memberikan sumbangan pada metode penelitian komunikasi untuk menemukan makna yang purna (sensus plenior) dari segala sesuatu yang ada (being).

\section{END NOTE}

[1] Homeros hidup sekitar abad 8 sebelum Masehi. Jika diakui sebagai karya Homeros maka Ililiad dan Odyssey diperkirakan lahir bersamaan waktunya dengan masa kehidupan sang penciptanya. Boleh dikatakan bahwa epik tersebut adalah awal mula dari literatur Barat yang selanjutnya sangat mempengaruhi sejarah sastra.

[2] Sebagaimana diketahui dalam karya Aristoteles, Organon, salah satu dia antaranya De Interpretatione ini atau dalam bahasa Yunaninya Peri Hermenias. Karya ini terdiri atas delapan bab, pada intinya dibahas di dalamnya hubungan antara bahasa dan logika. Selengkapnya lihat Aristotle's Categories and Propositions (De interpretatione), 1980.

[3] Lihat misalnya Davidson, The Old Testament (1857) di mana Aklitab secara hermeneutis dikritisi latar teksnya, dengan metode hermeneutika yakni dengan mengkritisi (interpretasi) teks tersebut dalam hubungannya dengan tradisi dan sejarah bangsa Ibrani pada saat teks itu ditulis.

[4] Leon Festinger misalnya, dalam teori $\mathrm{Cog}$ nitive Dissonace menekankan tiga efek komunikasi yang jika dicermati dengan saksama mirip dengan bangun segitiga Origenes.

[5] Dari kata Yunani anagoge yang secara harfiah berarti: "naik" atau "pendakian".

[6] Untuk melihat bagaimana pengaruh fenomenologi demikian kuat dalam diri Gadamer, baca misalnya Wachterhauser, Hermeneutics and Modern Philosophy (1986).

[7] Sedemikian kuatnya pengaruh Heidegger pada Gadamer dilukiskan Palm- 
er sebagai berikut "...then a German philosopher, Hans-Georg Gadamer, who had been Heidegger's assistant for five years in Marburg, from 1923-1928, while Heidegger was writing Being and Time,came to see in Heidegger's thought-both in Being and Time and in the 1935 essay, "Der Ursprung des Kunstwerkes"("The Origin of the Work of Art," pp. 139-212 in Heidegger, Basic Writings) the basis for a "philosophical hermeneutics." Hermeneutika Gadamer yang menekankan interpretasi dalam bingkai waktu sejarah dan tradisi ada benang merahnya dengan karya Heidegger, Being and Time.

[8] Metode dalam bahasa Latin, methodus yang diderivasi dari kata Yunani, méthodos (metá: sesudah dan hodós: jalan) yang secara harfiah berarti: orang yang mengikuti jalan tertentu.

[9] Untuk mendalaminya, baca buku The Symbol of Evil (1967) Paul Ricoeur yang diterjemahkan E. Buchanan.

[10] Berger dan Luckmann dalam buku Social Construction of Reality (1966) membahas sosiologi pengetahuan dan melihat bahwa apa yang disebut dengan "realitas" ialah hasil dari konstruksi sosial yang menjadi nyata dalam kerangka sejarah. "...Humans do construct social life, but this social life, becomes real, a series of 'social facts'. This can be seen clearly in historical terms - and the famous 'castaways on a desert island' example make this clear."

[11] Oleh karena cita rasa prejudice dalam bahasa Inggris kurang sanggup mentransfer seluruhnya cita rasa vorurteil dalam bahasa Jerman, banyak pakar tidak menggunakan bahasa Inggris, tetapi tetap mempertahankan aslinya. Ini juga dapat dilihat sebagai bagian dari proses hermeneutika di mana istilah tersebut coba dicari makna hakikinya.

[12] Kamus Besar Bahasa Indonesia, 2007: 35.

\section{DAFTAR PUSTAKA}

Agushevits, Reuven. 2008. Principles of Phi losophy. Jersey City: KTAV Publishing House.

Apostle, Hippocrates George (terj.) 1980. Aris totle's Categories and Propositions (De interpretatione). California:Peripatetic Press.

Barret, William dan Henry David Aiken. 1962. Philosophy in the Twentieth Century: An Anthology, Volume 1. New York: Random House.

Berger, P. dan Luckmann T. 1966. The Social Construction of Reality: A Treatise on the Sociology of Knowledge. London: Penguin University Books.

Bertens, K. 1999. Sejarah Filsafat Yunani. Yo gyakarta: Kanisius.

Boldonova, Irina. 2008. “On H.G. Gadamer's Truth and Method: The Hermeneutics of Interpersonal Communica tion" dalam William Sweet (ed.), The Dialoque of Cultural Traditions: A Global Perspec tive. Washington: The Council for Research in Values and Philosophy.

Caroll, Robert P. 2002. "Removing An Ancient Landmark: Reading The Bible as Cul tural Production" dalam Martin O'Kane (ed.), Borders, Boundaries and the Bible. New York: Sheffield Academic Press ltd.

Davidson D.D., Samuel. 1857. The Text of the Old Testament. London: Longman.

Deetz, Stanley. 1976. “Gadamer's Hermeneu tics and American Communication Studies", paper presented at the Annual International Colloquium on Verbal Communication.

Gadamer, Hans-Georg. 1975. Truth and Meth od. London-New York: Continuum.

Grant, Edward. 1996. The Foundations of Modern Science in The Middle Ages:

Their Religious, Insti

tutional, and Intellectual Con text. Cambridge: Cambridge University Press. Littlejohn, Stephen W. dan Karen A. Foss (edi 
tors). 2009. Encyclopedia of Communi cation Theory. California: Sage.

Ricoeur, Paul. 1973 "The Hermeneutical Function of Distanciation" dalam Phi losophy Today 17.

1967. The Symbol of Evil (ter jemahan oleh E. Buchanan. New York: Harper \& Row. 1991. From Text to Action: Es says in Hermeneutics, II. Illio nis: Northwestern University Press.

Seiler, Georg Friedrich, Jodocus Heringa
\&William Wright. 1835. Bibli cal Hermeneutics; or, The Art of Inter pretation. London: Kessinger Publishing. Vatimmo, Gianni. 1997. Beyond Interpreta tion: The Meaning of Hermeneutics of Philosophy. Standford, Califor nia: Standford University Press.

Wachterhauser, Brice R. (ed.). 1986. Herme neutic and Modern Philosophy. New York: State University of New York. http://plato.stanford.edu/entries/aristotle-log ic/ diunduh pada 5 Maret 2011. 